УДК 658.512.23

13.00.00 Педагогические науки

ПЕДАГОГИЧЕСКАЯ МОДЕЛЬ КАК СРЕДСТВО ПОВЫШЕНИЯ КАЧЕСТВА ПОДГОТОВКИ СТУДЕНТОВ-ДИЗАЙНЕРОВ

Кольцова Елена Анатольевна стажер

Институт художественного образования и культурологии Российской академии образования, Россия

E-mail: elen112008@yandex.ru

В статье рассматривается проблема повышения качества профессионального образования. В качестве средства эффективной подготовки специалистов в области дизайна предлагается педагогическая модель формирования профессиональных компетенций студентовдизайнеров. Базой формирования модели служит принцип композита, механизмом реализации модульная программа. Структура модели включает смысловой, содержательно-организационный, оценочно-результативный блоки. Результатом применения модели является сформированность профессиональных компетенций будущих дизайнеров в области проектной и художественной деятельности, что соотносится с

компетентностным контекстом в системе высшего образования

Ключевые слова: ПЕДАГОГИКА, ДИЗАЙН, ОБРАЗОВАНИЕ, ПРОФЕССИЯ, КОМПЕТЕНЦИЯ, ПЕДАГОГИЧЕСКАЯ МОДЕЛЬ, ПРИНЦИП КОМПОЗИТА, МОДУЛЬНАЯ ПРОГРАММА

Doi: 10.21515/1990-4665-131-089
UDC 658.512 .23

Pedagogical sciences

\section{PEDAGOGICAL MODEL AS A TOOL FOR IMPROVING QUALITY OF TRAINING OF STUDENTS-DESIGNERS}

\author{
Koltsova Elena Anatolyevna \\ Intern \\ Institute of Arts Education and Culturology of Russian \\ Academy of Education, Russia \\ E-mail: elen112008@yandex.ru
}

\begin{abstract}
The article discusses the problem of improving the quality of vocational education. The pedagogical model of the formation of professional competences of the students-designers is proposed as a way of effective training of specialists in the field of design. The principle of composite is the basis for the formation of the pedagogical model. The modular program is the mechanism of implementation of the pedagogical model. The structure of the pedagogical model includes next blocks: the semantic, the contentorganizational and the evaluation-productive. The result of the application of the pedagogical model is the formation of the professional competencies of future specialists in the field of design, which correlates with the competence context in the system of higher education
\end{abstract}

Keywords: PEDAGOGY, DESIGN, EDUCATION, PROFESSION, COMPETENCE, PEDAGOGICAL MODEL, PRINCIPLE OF COMPOSITE, MODULAR PROGRAM

В настоящее время профессиональная подготовка дизайнеров, как и специалистов любой сферы деятельности, решается в контексте компетентностного похода, который призван решить проблему несоответствия качества образования потребностям современной экономики и социума. Новые общественно-экономические реалии, характеризующиеся глобализацией, инновациями и динамизмом, интеграцией и сетевым взаимодействием, требуют от индивидуума умения делать выбор, способности решать проблемы различной сложности на основе имеющихся знаний и опыта, постоянного саморазвития и самосовершенствования, готовности к переменам. Компетентностный подход акцентирует внимание http://ej.kubagro.ru/2017/07/pdf/89.pdf 
на компетенции как результате обучения, интегральном качестве личности, позволяющем выпускнику вуза результативно осуществлять трудовую деятельность, успешно адаптироваться в профессии Уровень сформированности компетенций определяется как качественная характеристика подготовленности выпускника вуза, обеспечивающая его профессиональную мобильность и социальную защищенность.

Смена приоритетов и социальных ценностей потребовала коренного изменения стратегии и тактики обучения в вузе. Современные вузы ориентированы на поиск и внедрение в образовательный процесс педагогических новаций, обеспечивающих соответствие выпускников выдвигаемым требованиям социума и государства. В том числе реконструкции подвергается система традиционных методов и форм обучения. Например, в работе И.В. Алексеевой представлен био-адекватный релаксационно-активный метод развития творческих способностей студентов [1].

Поиск инновационных технологий подготовки специалистов обращает внимание педагогов к моделированию как средству оптимизации процесса обучения. Педагогическая модель представляет собой некий абстрактный объект, аналог исследуемого объекта или явления, отображающий структуру, свойства, взаимосвязи его элементов. Теоретическая модель отображает моделируемый объект только в каком-либо одном определенном отношении для сопоставления с которым она и создается, остальные свойства временно не принимаются во внимание. Построение теоретической модели, по мнению В.В.Краевского, позволяет выявить скрытое в силу сложности такого явления как педагогический процесс [2].

Предлагаемая педагогическая модель формирования профессиональных компетенций студентов-дизайнеров, ориентированных на прикладной вид деятельности, является средством повышения качества подготовки специалистов в области дизайна. Базой данной педагогической модели является принцип композита, сочетающий в себе вариабельность http://ej.kubagro.ru/2017/07/pdf/89.pdf 
методов, форм и средств обучения в единстве целей и задач образования, включающий оригинальную трактовку связи теории с практикой интерактивное освоение студентами-дизайнерами учебных дисциплин на основе исследования конкретных средовых объектов и создания дизайнпроектов их преобразования. Механизмом реализации данной модели служит модульная программа «Интегративное проектирование», в основе которой интеграция содержания предметов (проектирование, конструирование, эргономика, материаловедение, цветоведение) и профессиональных умений, формируемых в процессе учебной деятельности студентов.

Интеграция, как восстановление единства, естественной целостности познавательного процесса, служит инструментом повышения эффективности профессионального образования путем объединения знаний из разных областей науки, формирования научного мировоззрения студентов и таких качеств личности как креативность, самостоятельность, коммуникативность. Принципы построения интеграционного образовательного пространства раскрываются в работах И.Э. Кашековой [3].

Гармонично соединять художественное и утилитарное в создаваемых объектах дизайнеру позволяет особый синтетический тип мышления дизайн-мышление, основанное на способности человека к созданию идей, несущих не только функциональный, но и эмоциональный компонент. С одной стороны, проектный компонент мышления дизайнера способствует созданию новой реальности при объединении разных областей знаний и видов человеческой деятельности. С другой стороны, художественный компонент дизайн-мышления позволяет дизайнеру наполнять окружающий мир символами, смыслами и ценностями, образует самостоятельную эстетическую ценность современных произведений дизайна.

С учетом специфики профессии, на основе анализа содержания и структуры проектно-художественной деятельности дизайнера осуществлялось проектирование данной педагогической модели. Предметность деятельности дизайнера определила состав программы http://ej.kubagro.ru/2017/07/pdf/89.pdf 
«Интегративное проектирование». Структурные компоненты педагогической модели: смысловой, содержательно-организационный и оценочнорезультативный блоки. Смысловой блок модели обусловлен социальным заказом и квалификационными требованиями к специалисту в области дизайна уровня бакалавриат, ориентирован на деятельностный, компетентностный, интегративный и культурологический подходы в образовании.

Федеральные государственные образовательные стандарты по направлению подготовки 54.03.01 Дизайн предусматривают дифференциацию программы подготовки бакалавриата на академический и прикладной, и устанавливают каждому виду деятельности определенные профессиональные компетенции [4]. Таким образом, смысловой блок модели отражает реализацию социального заказа на компетентных специалистов в области дизайна по проектно-художественному виду профессиональной деятельности.

Цели и задачи смыслового блока решаются следующими компонентами организационно-содержательного блока: комплексом психолого-педагогических условий, организационных форм и средств обучения, педагогических методов, модульной программой «Интегративное проектирование».

Выявить уровень сформированности профессиональных компетенций студентов-дизайнеров, ориентированных на прикладной вид деятельности и определить эффективность данного процесса позволяет оценочнорезультативный блок модели, включающий мотивационно-ценностный, когнитивный, деятельностный и личностный компоненты.

Таким образом, структура педагогической модели во взаимосвязи всех ее компонентов позволяет рассмотреть в единой системе процесс формирования профессиональных компетенций студентов-дизайнеров, ориентированных на прикладной вид деятельности.

Структура модели представлена в таблице. 


\section{Педагогическая модель формирования профессиональных компетенций студентов-дизайнеров, ориентированных на} прикладной вид деятельности

\begin{tabular}{|c|c|c|c|c|}
\hline \multicolumn{5}{|c|}{ 1. Смысловой блок } \\
\hline \multicolumn{5}{|c|}{ Цель: формирование профессиональных компетенций студентов-дизайнеров, ориентированных прикладной вид деятельности } \\
\hline \multicolumn{5}{|c|}{$\begin{array}{l}\text { Задачи: 1. сформировать систему знаний о способах организации эстетически выразительной предметно-пространственной и } \\
\text { архитектурной среды; } \\
\text { 2. развить способность обосновывать проектные идеи, базирующиеся на концептуальном, творческом подходе к решению } \\
\text { дизайнерской задачи; } \\
\text { 3. выработать способность выполнять комплексные дизайн-проекты на основе методики ведения проектно-художественной } \\
\text { деятельности; } \\
\text { 4. сформировать способность к реализации компетенций в проектной и художественной деятельности на практике } \\
\vee\end{array}$} \\
\hline \multicolumn{5}{|c|}{ Методологические подходы: деятельностный; компетентностный; интегративный; культурологический } \\
\hline & 2. $\mathrm{C}$ & кательно-организацион & Ій блок & \\
\hline & & & & \\
\hline & $\frac{\text { Условия формировани }}{\vee}$ & фессиональных компете & $\frac{\text { ий студентов-дизайнер }}{\vee}$ & \\
\hline & ологические & & Педагоги & \\
\hline$\downarrow$ & $\downarrow$ & & $\downarrow$ & $\downarrow$ \\
\hline $\begin{array}{c}\text { Творческая } \\
\text { образовательная среда }\end{array}$ & $\begin{array}{c}\text { Мотивация } \\
\text { профессиональной } \\
\text { деятельности }\end{array}$ & $\begin{array}{c}\text { Тренинг по развитию } \\
\text { дизайнерского } \\
\text { мышления }\end{array}$ & $\begin{array}{c}\text { Владение } \\
\text { современными } \\
\text { средствами } \\
\text { проектирования }\end{array}$ & $\begin{array}{c}\text { Организация процесса } \\
\text { обучения } \\
\text { на принципах }\end{array}$ \\
\hline$\vee$ & $\downarrow$ & $\boldsymbol{v}$ & $\downarrow$ & 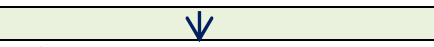 \\
\hline $\begin{array}{ll} & \text { создание атмосферы } \\
& \text { творчества, } \\
\text { соревновательности; } \\
\checkmark \\
\text { взаимодействие на } \\
\text { основе интеракции; }\end{array}$ & $\begin{array}{ll}\checkmark & \text { посещение } \\
& \text { профессиональных } \\
& \text { выставок; } \\
\checkmark & \text { участие в выставках, } \\
& \text { конкурсах дизайна; }\end{array}$ & \begin{tabular}{|l|} 
Формы работы: \\
индивидуальные; \\
групповые; \\
самостоятельная работа \\
\multicolumn{1}{c|}{$\downarrow$} \\
Творческие задачи и \\
\end{tabular} & $\begin{array}{ll}\checkmark & \text { информационными } \\
& \text { технологиями; } \\
\checkmark & \text { графическими } \\
& \text { программами; } \\
\checkmark & \text { компьютерными }\end{array}$ & $\begin{array}{ll}\checkmark & \text { композита; } \\
\checkmark & \text { интегративности и } \\
& \text { межпредметности; } \\
\checkmark & \text { квазипрофессиональ- } \\
& \text { ности; }\end{array}$ \\
\hline
\end{tabular}

http://ej.kubagro.ru/2017/07/pdf/89.pdf 


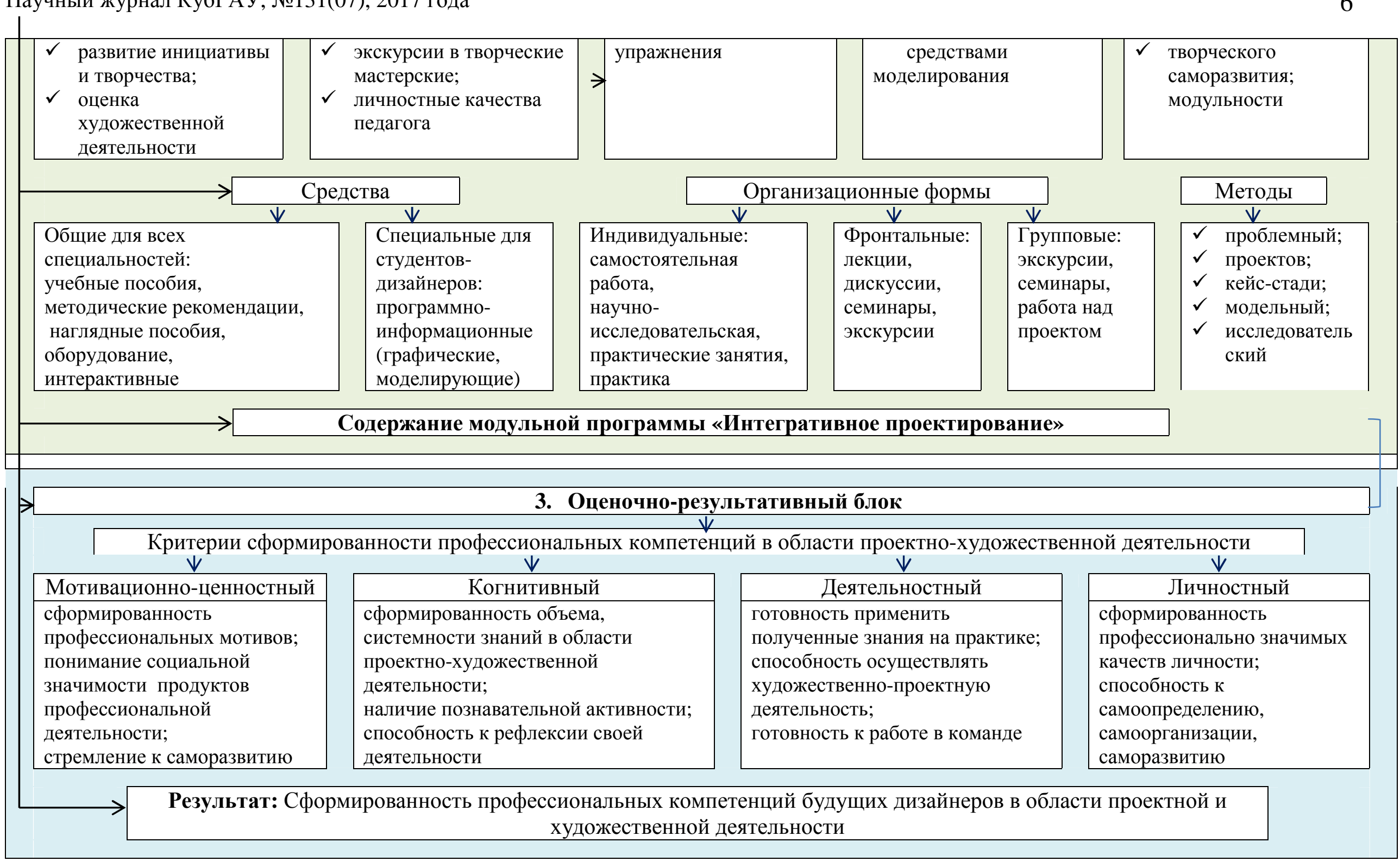




\section{Ссылки:}

1. Алексеева И.В. Развитие художественно-творческих способностей студентов к декоративно-прикладной деятельности [Текст] / И.В. Алексеева: Дисс...докт. пед. Наук. М., 2005. - 540 c.

2. Краевский В.В. Общие основы педагогики [Текст] / В.В. Краевский: Учеб. пособие для студ. высш. пед. учеб. заведений. - 2-е изд., испр. - М., Академия, 2005. $256 \mathrm{c}$.

3. Кашекова И.Э. Технология интеграции и конвергентности с искусством в предпрофильном и профильном образовании// Электронный научный журнал «Педагогика искусства». - 2008. - URL: http://www.art-education.ru/electronicjournal/tehnologiya-integracii-i-konvergentnosti-s-iskusstvom-v-predprofilnom-i-profilnom (дата обращения: 29.08.2017).

4. ФГОС ВО по направлению подготовки 54.03.01 Дизайн (уровень бакалавриата) [Электронный pecypc] // Федеральный портал «Российское Образование». URL: http://fgosvo.ru/uploadfiles/fgosvob/540301.pdf (дата обращения: 29.08.2017).

\section{References:}

1. Alekseeva I.V. Razvitie hudozhestvenno-tvorcheskih sposobnostej studentov $\mathrm{k}$ dekorativno-prikladnoj dejatel'nosti [Tekst] / I.V. Alekseeva: Diss...dokt. ped. Nauk. - M., 2005. $-540 \mathrm{~s}$.

2. Kraevskij V.V. Obshhie osnovy pedagogiki [Tekst] / V.V. Kraevskij: Ucheb. posobie dlja stud. vyssh. ped. ucheb. zavedenij. - 2-e izd., ispr. - M., Akademija, 2005. - 256 s.

3. Kashekova I.Je. Tehnologija integracii i konvergentnosti $\mathrm{s}$ iskusstvom $\mathrm{v}$ predprofil'nom i profil'nom obrazovanii// Jelektronnyj nauchnyj zhurnal «Pedagogika iskusstva». - 2008. - URL: http://www.art-education.ru/electronic-journal/tehnologiya-integracii-ikonvergentnosti-s-iskusstvom-v-predprofilnom-i-profilnom (data obrashhenija: 29.08.2017).

4. FGOS VO po napravleniju podgotovki 54.03.01 Dizajn (uroven' bakalavriata) [Jelektronnyj resurs] // Federal'nyj portal «Rossijskoe Obrazovanie». URL: http://fgosvo.ru/uploadfiles/fgosvob/540301.pdf (data obrashhenija: 29.08.2017). 